\title{
Influence of Solidification Microstructure and Distribution of Reinforcement on Fatigue Characteristics of Notched SiC Reinforced AC4B Alloy Composites
}

\author{
Hirofumi Miyahara, Yusaku Maruno* and Keisaku Ogi \\ Department of Materials Science and Engineering, Graduate School of Engineering, Kyushu University, Fukuoka 812-8581, Japan
}

The influences of $\mathrm{SiC}$ particle distribution, surface notch size and solidification microstructure of the matrix on the fatigue characteristics of $\mathrm{SiC}$ reinforced JIS-AC4B alloy composites were investigated. Al-6.79 mass\% Si-2.93 mass\% Cu-0.17 mass\% Mg-0.59 mass\% Fe matrix composites with relatively homogeneously dispersed $11 \mu \mathrm{m} \mathrm{SiC} \mathrm{particles} \mathrm{were} \mathrm{fabricated} \mathrm{through} \mathrm{a} \mathrm{combination} \mathrm{of} \mathrm{pressure} \mathrm{infiltration} \mathrm{and} \mathrm{a}$ melt stirring casting method. The matrix microstructure consisted of a dendritic alpha phase and eutectic Si with a few volume fractions of Fe intermetallic compound among the dendrites. All specimens contained some gas and shrinkage porosities, and all composite specimens contained SiC particle clusters. Vickers hardness of composites clearly increases due to the dispersion of SiC particles and age hardening. The hardening ability increases with an increasing volume fraction of SiC. Rotating bending fatigue tests were carried out on notch-free and notched specimens that had peak aging. In the notch-free matrix alloy specimen, cracks generated from porosities, whereas cracks generated from the $\mathrm{SiC}$ particles/the matrix interfaces in the composite specimens. Thus, the fatigue strength decreased with an increase in the $\mathrm{SiC}$ volume fraction. In the notch-introduced matrix alloy specimen, where the stress concentration factor is high, the notch becomes the crack generation site and dominated the fatigue strength. The cracks, however, generate near SiC particles instead of the notch bottom in the composite specimen. Moreover, it was found that the fatigue limit stress is unchanged in composite specimen even when the notch is introduced, although the critical stress for crack generation declines. Microstructural observation revealed that the cracks were spread and diverted in and around the cluster of $\mathrm{SiC}$ particles, suggesting that crack propagation resistance was improved in the composite specimen.

(Received November 29, 2004; Accepted February 28, 2005; Published May 15, 2005)

Keywords: cast composites, ceramics particle, notch, solidification, non-propagating crack, crack generation stress, fatigue limit stress

\section{Introduction}

In recent years, the development of composite materials that disperse ceramics particles in an aluminum alloy has advanced, to produce new materials that meet the strength, heat-resistant and abrasion-resistant improvements required for transport machines and various kinds industrial machines. Since SiC particles have a higher Young's modulus, superior hardness, high temperature stability, abrasion resistance, thermal shock resistance and better wettability to molten aluminum alloy, it is conceivable that $\mathrm{SiC}$ particles will be suitable for the reinforcement of aluminum alloy composites. ${ }^{1-3)}$ The use of casting as the manufacturing process for $\mathrm{SiC} / \mathrm{Al}$ alloy composites has the advantages of a short processing time and the absence of the requirement for secondary processing, which is especially advantageous for products with complicated shapes, although the casting temperature is relatively high. ${ }^{4,5)}$ Mechanical properties such as the tensile strength, stiffness, abrasion resistance and fatigue properties of $\mathrm{SiC}$ particle reinforced aluminum alloy composites have been reported. ${ }^{6-11)}$ Toda et al. developed the theory when the crack progress into ceramics particle reinforced alloy, and pointed out that the micro-crack, stress concentration, plastic deformation and deposition of reinforcement from matrix changed the crack propagating direction. ${ }^{11)}$ Murakami summarized the influence of notch size effect on fatigue characteristics of several standard alloys and proposed the nonpropagating crack govern the fatigue life. ${ }^{12)}$ However, there is comparatively little data that evaluate the notch effect on the fatigue characteristics of cast composite materials, although notches are present on their surfaces, resulting from the roughness on the surfaces of sand molds and permanent molds.

*Graduate Student, Kyushu University
In this work, the technique of dispersing $\mathrm{SiC}$ particles (from 10 to $30 \%$ in volume) in a JIS-AC4B matrix alloy by the combination of pressure infiltration and melt stirring was investigated. Then, the fatigue characteristics of the composites were investigated in relation to the solidification microstructure, the volume fraction and the distribution of particles. Furthermore, we evaluated the influence of an artificially-introduced notch on fatigue crack generation and propagation.

\section{Experimental Procedure}

SiC particle (Fujimi Incorporated Company Ltd., mean diameter $11 \mu \mathrm{m}$, with 0.63 mass $\% \mathrm{SiO}_{2}$ and 0.36 mass\% $\mathrm{C}$ (hereafter abbreviated as \%) impurities) was used for the reinforcement and a commercially available Japanese industrial standard AC4B alloy (Al-6.79\% Si-2.93\% Cu-0.17\% $\mathrm{Mg}-0.49 \% \mathrm{Mn}-0.59 \% \mathrm{Fe}-0.17 \% \mathrm{Zn}-0.03 \% \mathrm{Sr}$ ) was used for the matrix alloy. We combined pressure infiltration and meltstirring techniques to obtain a suitable volume fraction of $\mathrm{SiC}$ particles. The pressure infiltration unit is composed of a metallic mold, a cylinder for pressure and a control unit, and can produce pressures up to $50 \mathrm{MPa}$, which is high enough to squeeze pores inside the cast composites. The melt-stirring unit is composed of a furnace, a stirring impeller, and a temperature control unit. Flux powder and Ar gas can clean the melt surface and prevent oxidation.

First, AC4B alloy and SiC particles were preheated to $1073 \mathrm{~K}$ in a graphite crucible and $873 \mathrm{~K}$ in an alumina crucible, respectively. The preheated $\mathrm{SiC}$ particles were placed in a cylindrical permanent mold, and then molten AC4B alloy was immediately cast and infiltrated at a pressure of $50 \mathrm{MPa}$, for $180 \mathrm{~s}$, until solidification completed. The volume fraction of obtained composite block was about $50 \%$. This composite block and AC4B alloy block were remelted in 
the melt-stirring unit to attain the specified particle volume fractions to 10 to $30 \%$ under $0.2 \%$ flux $\left(5 \mathrm{MgCl}_{2}+3 \mathrm{KCl}+\right.$ $2 \mathrm{MgF}_{2}$ ) and Ar gas. Stirring was carried out for $3600 \mathrm{~s}$ at $60 \mathrm{rpm}$, on the basis of pre-experimental results, because the particles had a tendency to drop to the bottom with low speed mixing and distribute on the side wall as a result of centrifugal force at high speed mixing. A Sr equivalent about $300 \mathrm{ppm}$ was added into the molten metal for modification of eutectic $\mathrm{Si}$, and this mixture was then stabilized at $935 \mathrm{~K}$ for $600 \mathrm{~s}$. Molten alloy with SiC particles were cast into a cylindrical permanent mold and solidified again. Test piece was machined to a $62 \mathrm{~mm}$ height, $10 \mathrm{~mm}$ thickness and $10 \mathrm{~mm}$ width, and performed to solution heat treatment for $36 \mathrm{ks}$ in a salt bath at $773 \mathrm{~K}$ and the specimen was then quenched in an ice water bath. Then, the specimens were aged for different times from $30 \mathrm{~min}(1800 \mathrm{~s})$ to $10^{4} \mathrm{~min}$ $\left(6 \times 10^{5} \mathrm{~s}\right)$ in a silicon oil bath at $433 \mathrm{~K}$.

The specimens for the tensile strength test and the fatigue test were machined with a lathe from the aged block that achieved the highest hardness during the aging process, as shown in Fig. 1. A sixty degree $\mathrm{V}$ form notch with a curvature radius of $0.1 \mathrm{~mm}$ and a depth of $0.5 \mathrm{~mm}$ was produced on the surface of the fatigue test piece. The bottom surface was polished using silicon carbide, alumina powder, and a diamond paste. An Ono-type rotating bending fatigue tester was used for fatigue testing using a bending moment of $15 \mathrm{Nm}$, a rotation rate of $50 \mathrm{~Hz}$ and a two-way sine wave at a response ratio $(R)$ of -1 . The relationship between the cycle number $(N)$ and load stress $(\sigma)$ that ruptured the specimen was investigated, and the fatigue limit stress was defined as the maximum stress under which no breaking occurred for over $10^{7}$ cycles. The non-propagating cracks on the surface of the notch bottom and at the cross section of cut specimens were observed using an optical microscope and a scanning

(a)
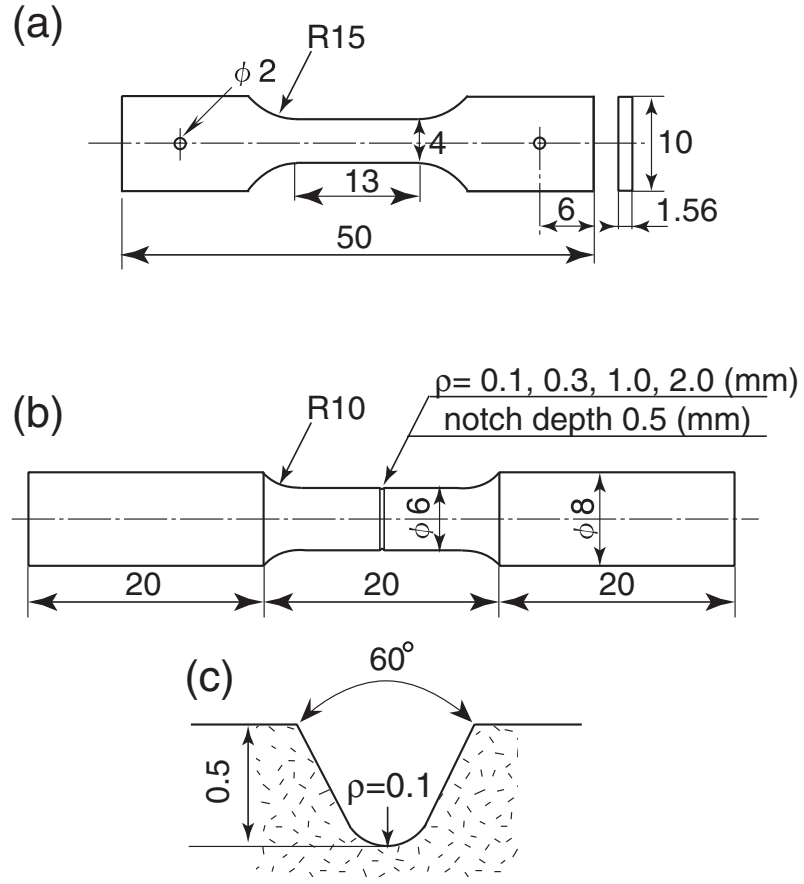

Fig. 1 Schematic view of the test pieces for the tensile strength test (a) and the fatigue test (b) with $\mathrm{V}$ form notch (c).
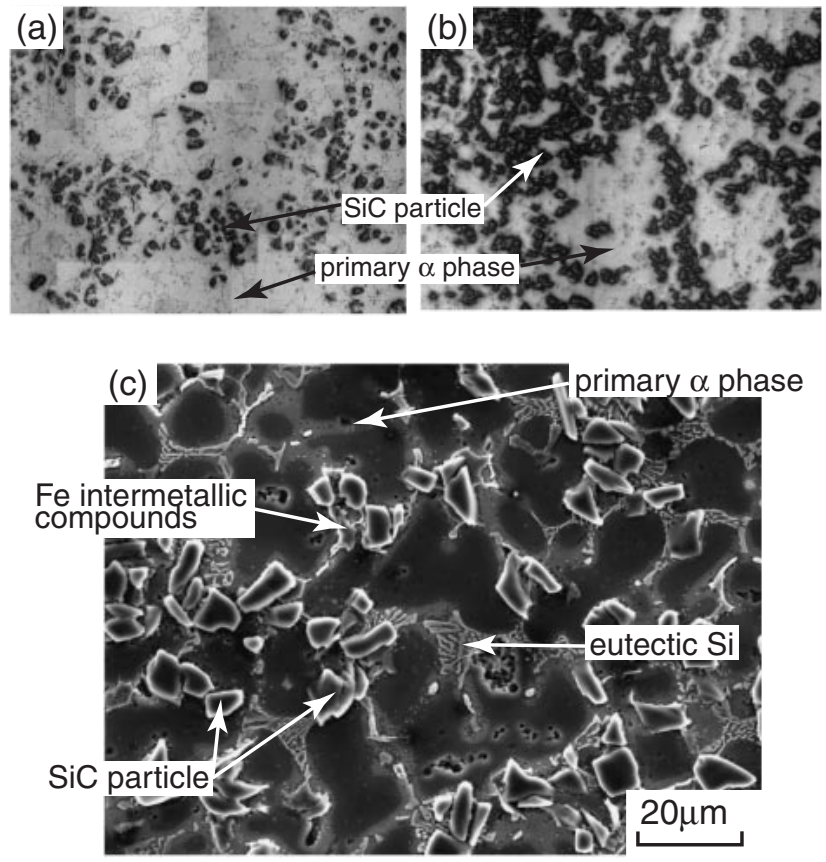

Fig. 2 Microstructures of the composite specimens containing $\mathrm{SiC}$ particles of $9.3 \%$ (a), and $31.4 \%$ (b, c) in volume observed by optical microscope $(a, b)$ and SEM (c).

electron microscope (SEM). The influences of the introducing notch, the solidification structure and the $\mathrm{SiC}$ particle distribution on the fatigue characteristics were investigated.

\section{Results and Discussion}

\subsection{Microstructure observation}

The microstructure of the composite material that achieved peak aging at $433 \mathrm{~K}$ after the solution treatment is shown in Fig. 2. The $\mathrm{SiC}$ particle volume fraction was close to the optimum fraction from the range 10 to $30 \%$, and the particles were distributed relatively homogeneously through the whole specimen. However, clusters of $\mathrm{SiC}$ particles ranging from several microns to several hundreds of microns in size were observed. The small cluster sizes result from primary $\alpha$ dendrites growing between the SiC particles, and the large ones may result from insufficient melt agitation. The solidification microstructure of the matrix consists of the primary $\alpha$ phase, the eutectic $\mathrm{Si}$ phase and Fe compounds $(\alpha$ $\mathrm{Al}_{15}(\mathrm{Fe}, \mathrm{Mn})_{3} \mathrm{Si}_{2}$ and $\left.\beta-\mathrm{Al}_{5} \mathrm{FeSi}\right)$. The Fe compound that is in contact with the SiC particle grew a little larger than the other Fe compounds as shown in Fig. 2(c). Blowholes and micro shrinkages of 5 to $150 \mu \mathrm{m}$ in size were also observed in the specimens. Figure 3 shows the secondary dendrite arm spacing $\left(\lambda_{2}\right)$ of each specimen. $\lambda_{2}$ became small when the particle volume fraction was increased. In addition, $\lambda_{2}$ was small in the high-density particle distribution within a specimen. Solute diffusion and the dendrite growth direction were restricted to a narrow channel, in comparison to in the unreinforced specimen.

\subsection{Age hardening sequence of $\mathrm{SiC}$ reinforced compo- site}

The age hardening sequences of the 9.3 vol\% and 


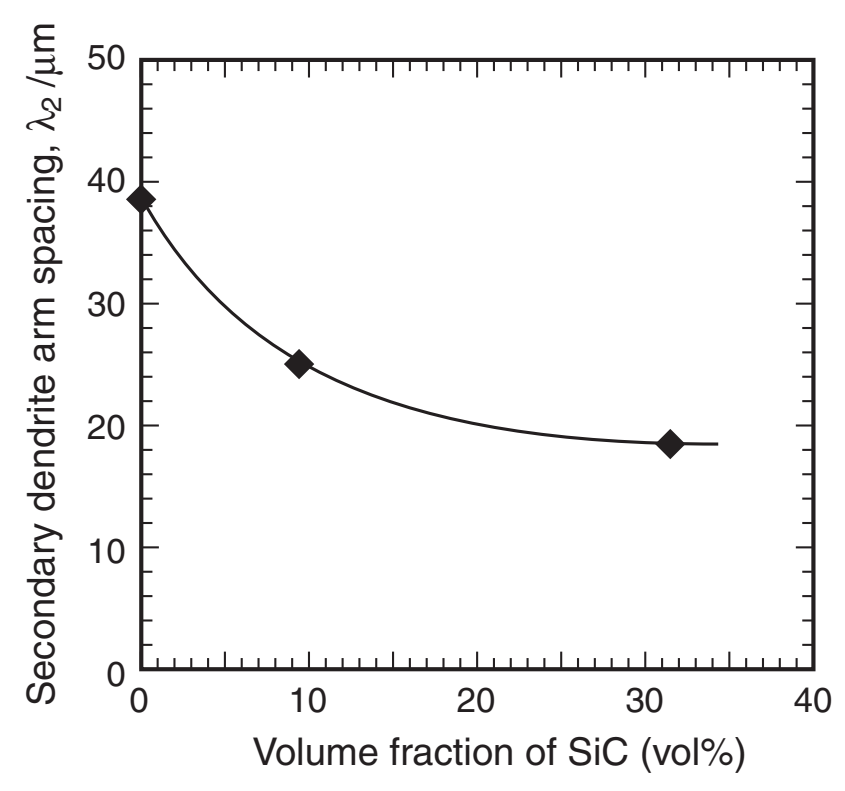

Fig. 3 Relationship between secondary dendrite arm spacing and SiC volume fraction.

31.4 vol\% specimens at $433 \mathrm{~K}$ are shown in Fig. 4. The matrix alloy results are shown for comparison. Matrix alloy is hardened by quenching after solution treatment and then aging at $433 \mathrm{~K}$. The hardness reaches $145 \mathrm{HV}$ after $840 \mathrm{~min}$ of aging (peak aging) and the peak hardening response $(\triangle H V)$ is $30 \mathrm{HV}$. Similarly, an increase in the hardness is observed even in the aging 9.3 vol\% composite materials. The hardening is caused by the $\mathrm{SiC}$ particles themselves and the dislocations introduced at the time of quenching, due to the thermal expansion coefficient difference between the particle and matrix, as reported for $\mathrm{Al}_{2} \mathrm{O}_{3} / \mathrm{AC}_{4} \mathrm{~B}^{13-15)}$ and $\mathrm{SiC} / \mathrm{Al}$ alloy ${ }^{16,17)}$ composites. Although the 9.3 vol\% composite hardens with aging, peak aging is achieved in a shorter period of time, $780 \mathrm{~min}$. A similar result was obtained for the 31 vol\% composite; a peak hardness of $220 \mathrm{HV}$ was reached in $660 \mathrm{~min}$. These results are summarized in Fig. 5. The aging response and the peak aging hardness increase with an increasing $\mathrm{SiC}$ volume fraction, but the time required to attain peak aging decreases. This is because the dislocations introduced in the vicinity of the $\mathrm{SiC}$ particles promotes the precipitation of phases such as the $\lambda^{\prime}\left(\mathrm{Al}_{5} \mathrm{Cu}_{2} \mathrm{Mg}_{8} \mathrm{Si}_{8}\right)$ and the $\theta^{\prime}\left(\mathrm{Al}_{2} \mathrm{Cu}\right)$ that contribute to aging. ${ }^{13)}$ In addition, as shown in Fig. 4(b), the difference of microhardness in the dendrite center is not influenced as much by $\mathrm{SiC}$, which indicates that the dislocations had no influence at large distances from the $\mathrm{SiC}$ particles. The specimen with the highest macro hardness was used for the tensile strength test and the fatigue test.

\subsection{Influence of particle distribution on tensile strength}

The mechanical properties of each specimen are shown in Table 1 . The tensile strength, $0.2 \%$ yield strength and elongation of the composite specimens are lower than those of the matrix alloy, and they decrease with an increase in the $\mathrm{SiC}$ volume fraction. The minute cracks that generate at eutectic $\mathrm{Si}$ and Fe compounds are observed in great numbers, and these cracks occur from a broken surface to a width of

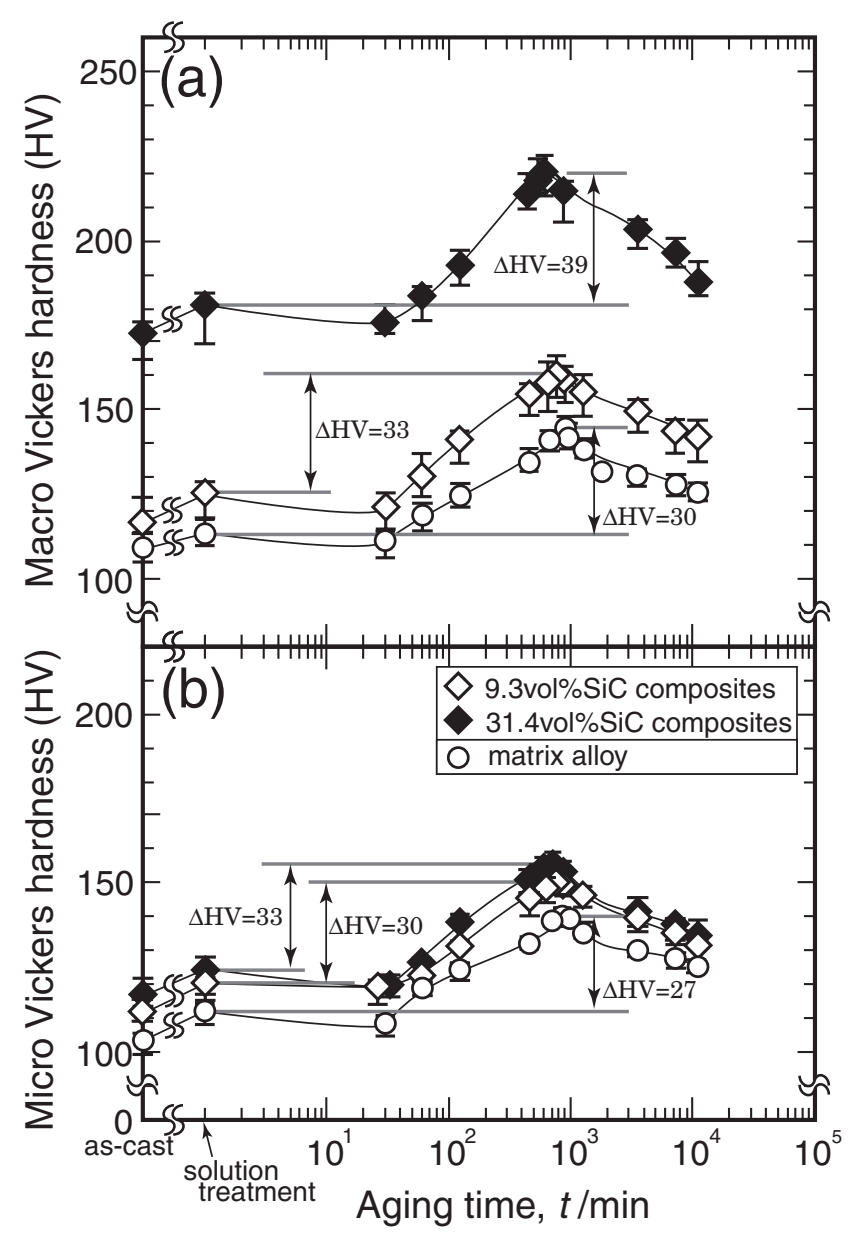

Fig. 4 Variation of macro Vickers hardness at a load of $20 \mathrm{~kg}$ (a) and micro Vickers hardness at $50 \mathrm{~g}$ (b) as the function of aging time at $443 \mathrm{~K}$ for 9.3 and $31.4 \mathrm{vol} \% \mathrm{SiC} / \mathrm{AC} 4 \mathrm{~B}$ alloy. The matrix alloy results are shown for comparison.

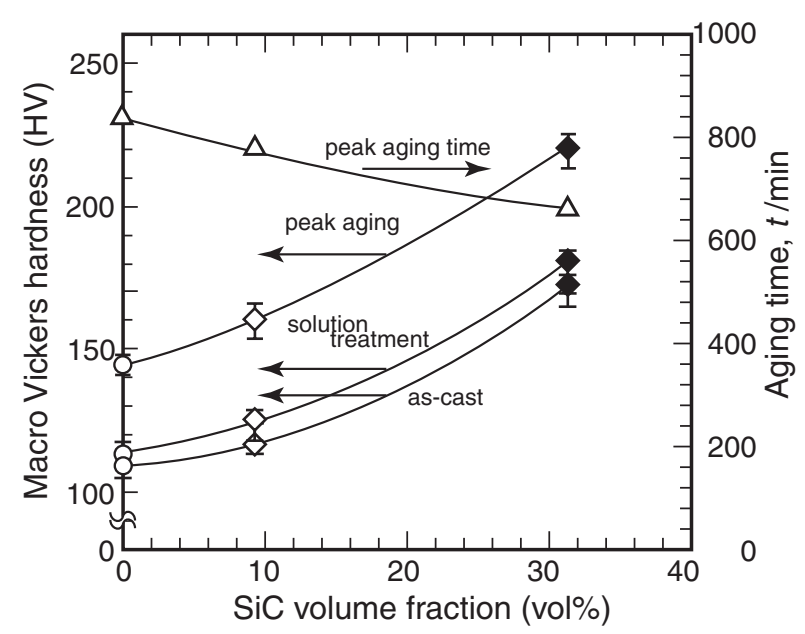

Fig. 5 Relationship between macro Vickers hardness and SiC volume fraction at the stage of as-cast, solution treatment, and peek aging. Peak aging time is accelerated with an increasing $\mathrm{SiC}$ volume fraction.

about $5 \mathrm{~mm}$ in the matrix alloy. This means that plastic deformation occurs over a comparatively wide area before the matrix specimens rupture. On the other hand, in the composite specimens, a few larger cracks were observed 
Table 1 Mechanical properties of matrix AC4B alloy and composite specimens.

\begin{tabular}{lccc}
\hline & $\begin{array}{c}\text { tensile strength } \\
\sigma_{\mathrm{B}}(\mathrm{MPa})\end{array}$ & $\begin{array}{c}\text { yield strength } \\
\sigma_{0.2}(\mathrm{MPa})\end{array}$ & $\begin{array}{c}\text { elongation } \\
\varepsilon(\%)\end{array}$ \\
\hline matrix alloy ${ }^{18)}$ & 345.2 & 287.0 & 1.58 \\
9.3 vol\% SiC composites & 315.2 & 279.1 & 0.94 \\
31.4 vol\% SiC composites & 299.3 & 268.9 & 140 \\
\hline
\end{tabular}

Table 2 The amount and size of the porosity in matrix AC4B alloy and composite specimens.

\begin{tabular}{lccc}
\hline & $\begin{array}{c}\text { maximum diameter } \\
(\mu \mathrm{m})\end{array}$ & $\begin{array}{c}\text { average diameter } \\
(\mu \mathrm{m})\end{array}$ & $\begin{array}{c}\text { number of particles } \\
\left(/ \mathrm{mm}^{2}\right)\end{array}$ \\
\hline matrix alloy & 25.0 & 4.5 & 23 \\
$9.3 \mathrm{vol} \% \mathrm{SiC}$ composites & 32.6 & 9.9 & 26 \\
31.4 vol\% SiC composites & 48.4 & 12.7 \\
\hline
\end{tabular}

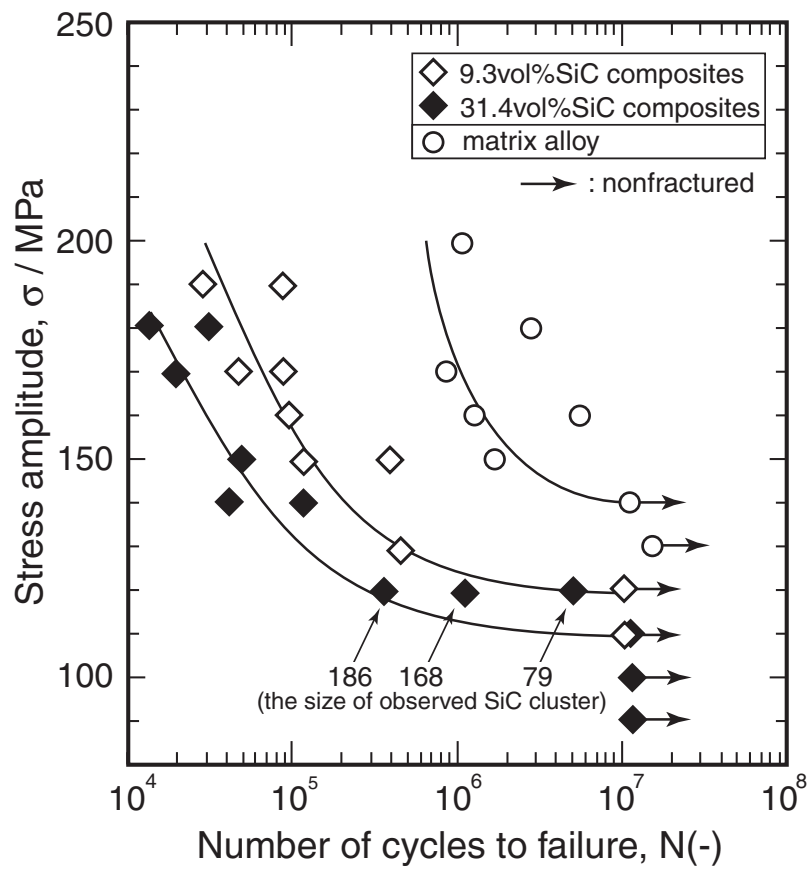

Fig. 6 Relationship between applied stress and number of cycles in the rotating bending fatigue test for notch-free composites and matrix alloy specimens. The arrows in the figure show that the specimen did not rupture even with a number exceeding $10^{7}$ cycles, so experiment stopped.

around $\mathrm{SiC}$ particles in the local area range of about $1 \mathrm{~mm}$ from the broken surface. Therefore, a cluster of $\mathrm{SiC}$ particles may concentrate stress, and immediately cause a crack and rupture.

\subsection{Influence of particle distribution on fatigue charac- teristics of notch-free specimen}

The results of the fatigue tests on the matrix alloy specimen and the $9 \mathrm{vol} \%$ and $31 \mathrm{vol} \% \mathrm{SiC}$ specimens are shown in Fig. 6. The arrows in the figure show that the specimen did not rupture even with a number $(N)$ exceeding $10^{7}$ cycles. Matrix alloy broke down before $N=10^{7}$ cycles at a stress over $\sigma=140 \mathrm{MPa}$, and the results were scattered. No breakdown occurred after $N=10^{7}$ cycles under a stress of $\sigma=140 \mathrm{MPa}$, thus the fatigue strength is judged to be $140 \mathrm{MPa}$. On the other hand, fatigue strengths were $110 \mathrm{MPa}$ and $120 \mathrm{MPa}$ for the $9 \mathrm{vol} \%$ and $31 \mathrm{vol} \%$ specimens, respectively. These values are lower than that of the matrix alloy and decrease with an increase in the $\mathrm{SiC}$ volume fraction. These results were also scattered, even though the specimens were machined from a single piece of composite block. It is generally recognized that experimental results for fatigue tests on notch-free specimens are significantly scattered, since there are differences in stress distribution and concentration in specimens even at the same nominal stresses, due to different internal cast defects, sizes, shapes and positions. ${ }^{18-21)}$ Therefore, the amount and size of the porosity were investigated, and both parameters were found to be higher in the composites, as shown in Table 2. Hence, the increase in the volume fraction of porosity could be one of the reasons for the decline in the fatigue strength.

However, a large amount of the fine non-propagating cracks from the clusters of $\mathrm{SiC}$ particles were observed at the specimen surface. The Young's moduli of the matrix alloy and the $\mathrm{SiC}$ particle are about $72 \mathrm{GPa}$ and $560 \mathrm{GPa}$, so the matrix alloy causes plastic deformation at the $\mathrm{SiC}$ particle/ matrix interface. Thus, the broken sections of the test pieces were analyzed by a scanning electron microscope. It was seen that cracks generate from several points on the specimen surface, and then progress radially toward the insides of the specimens, as shown by the arrows in Figs. 7(a) and 8(a). Moreover, clusters of $\mathrm{SiC}$ particle were observed where the cracks generated (Fig. 7(b), Fig. 8(b)). SiC particle clusters from 80 to $190 \mu \mathrm{m}$ in size were seen in the $31 \mathrm{vol} \%$ specimens corresponding to the data in Fig. 6. Accordingly, it is concluded that the cracks generate at the interfaces between SiC particles and the $\alpha$-dendrite, and that the clusters of $\mathrm{SiC}$ particles, rather than the porosity control fatigue crack generation in the composite materials. Furthermore, the fatigue results depend on the distribution of the size of $\mathrm{SiC}$ particle clusters inside each specimen (Fig. 6). Toda et al. conclude that the higher aspect ratio or sharp corner of the reinforcement results in the decreasing microscopic strain, ${ }^{11)}$ and Llorca et al. suggest that high volume fraction area has a tendency to become embrittled. ${ }^{22)}$ Thus, the crack can easily initiate vicinity of the $\mathrm{SiC}$ particle cluster, suggesting that fatigue limit stress can be increased if the SiC particles are distributed homogeneously and the cluster size is controlled to be small. In addition, since an uneven fracture surface is 

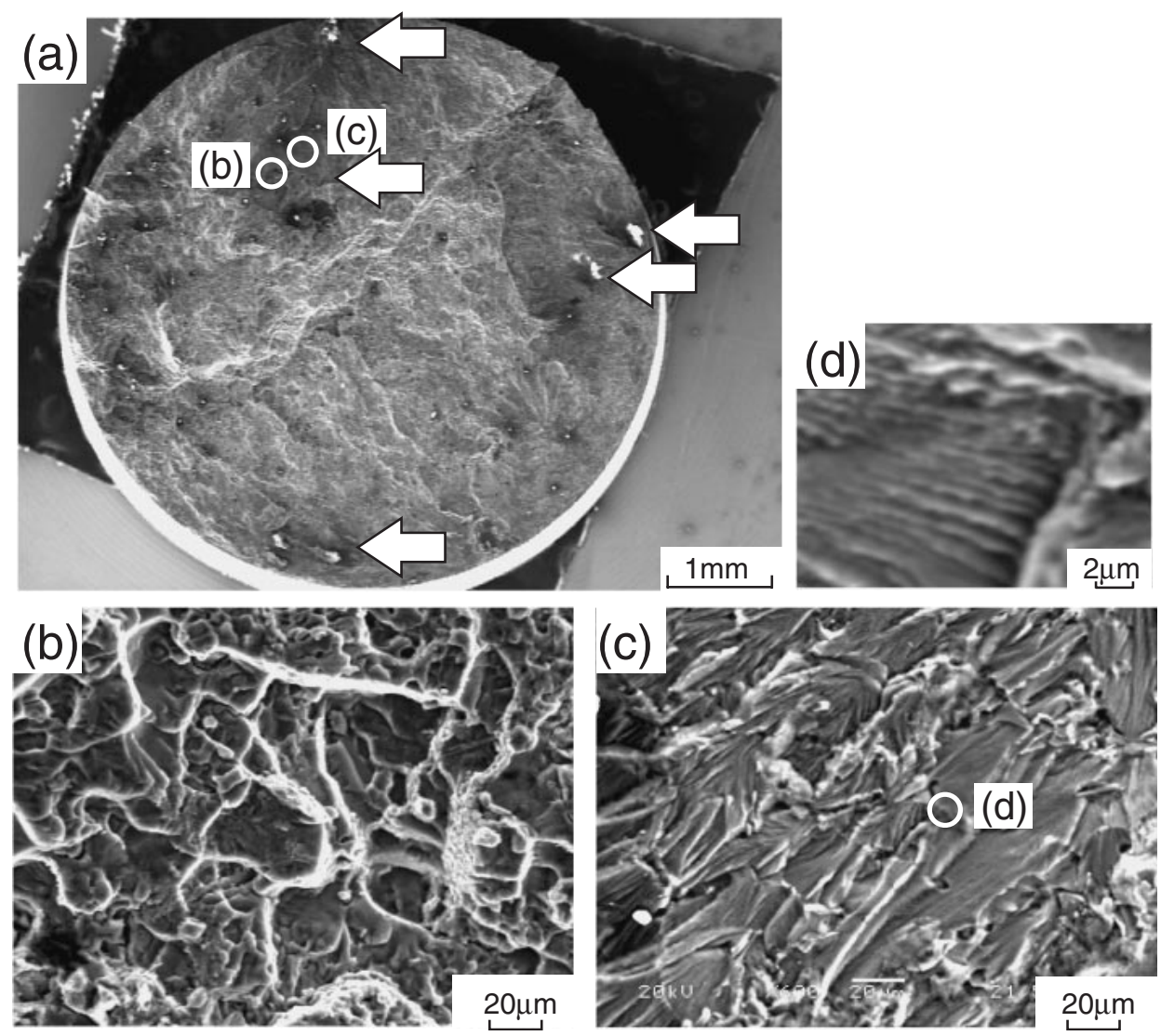

Fig. 7 Scanning electron micrographs of fractured surfaces for 9.3 vol\% $\%$ SiC $/ \mathrm{AC} 4 \mathrm{~B}$ composites in applied load of $130 \mathrm{MPa}$ (a). There are clusters of $\mathrm{SiC}$ particle (arrows in (a) and (b)), uneven fracture surface (c) and striation pattern (d) on the surface.
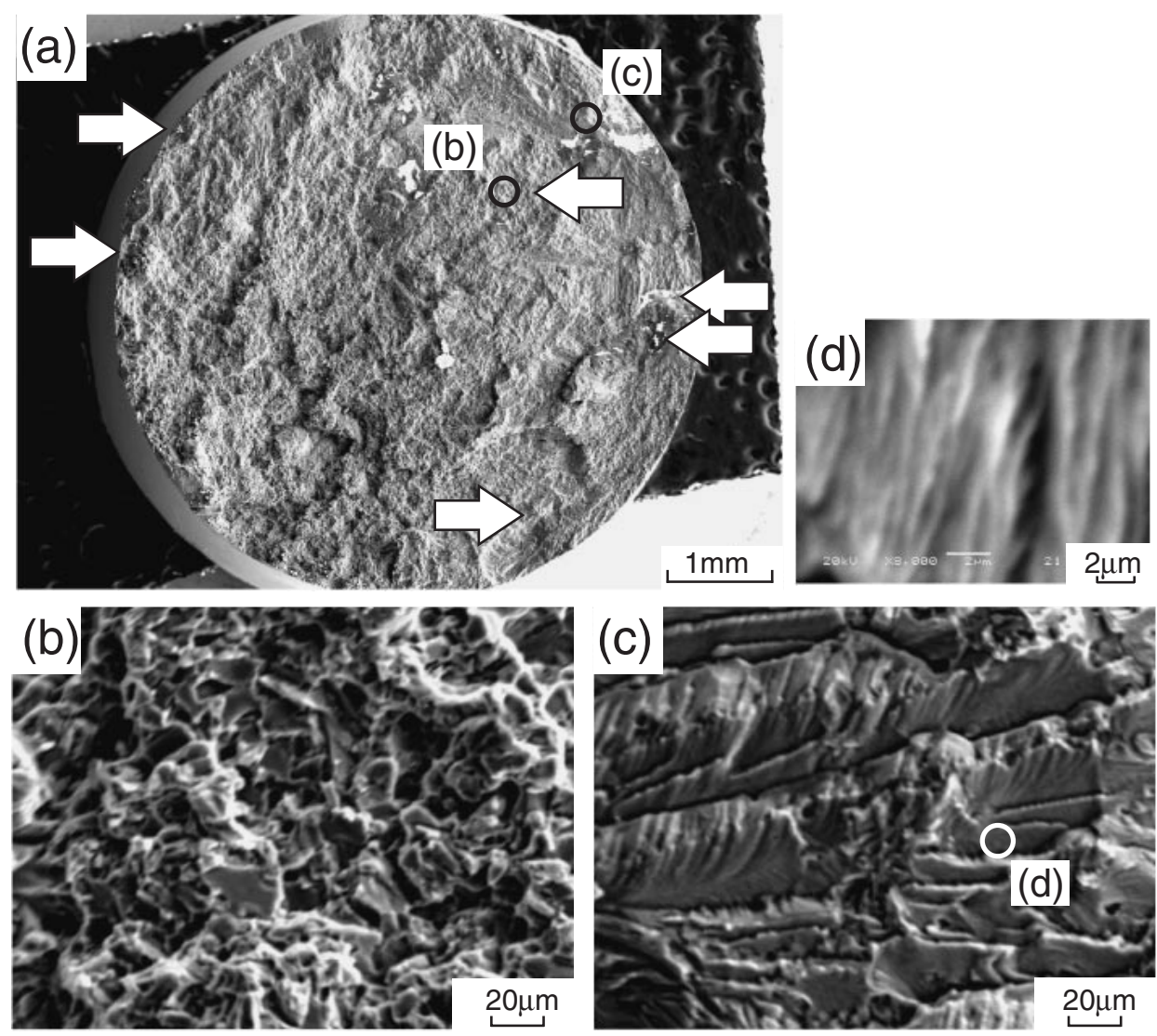

Fig. 8 Scanning electron micrographs of fractured surfaces for 31.4 vol\%SiC/AC4B composites in applied load of $120 \mathrm{MPa}$. 


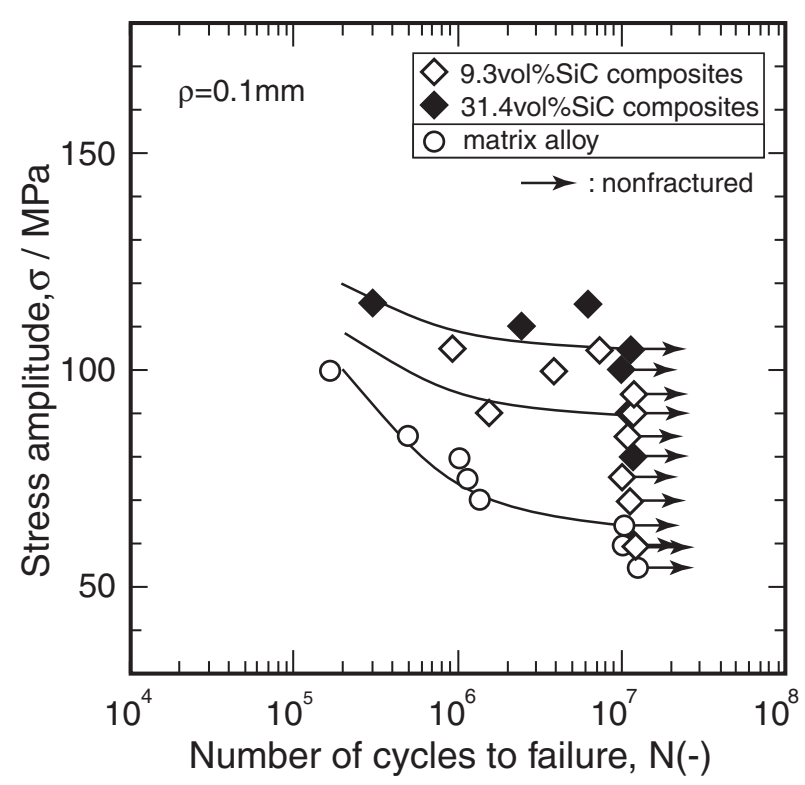

Fig. 9 Relationship between applied stress and number of cycles in the rotating bending fatigue test for notched composites and matrix alloy specimens $(\rho=0.1 \mathrm{~mm})$.

observed, as shown in Figs. 7(c) and 8(c), the destruction of the test piece might result from the repetition of the crack propagating step and the connection of separate cracks. The width of each striation pattern as shown in Figs. 7(d) and 8(d) suggests that the crack propagating step of the 9 vol\% $\mathrm{SiC}$ specimen after 1 cycle is smaller than that of the $31 \mathrm{vol} \%$ specimen under the a similar applied stress of 120-130 MPa.

\subsection{Influence of the notch on fatigue characteristics}

Figure 9 shows the $\mathrm{S}-\mathrm{N}$ curve obtained for the $0.1 \mathrm{~mm}$ notched specimens. The cycle number $(N)$ increases with a decline in the setting load, similarly to the case for the notchfree matrix alloy, and the notch fatigue strength was found to be $\sigma=65 \mathrm{MPa}$. On the other hand, the fatigue strengths of the composites become $95 \mathrm{MPa}$ and $105 \mathrm{MPa}$ for the $9 \mathrm{vol} \%$ and 31 vol\% SiC specimens, respectively. These values are higher than that for the matrix alloy. Furthermore, the fatigue limit strength increases as the $\mathrm{SiC}$ volume fraction increases. Thus, the macrostructure of the specimen that did not rupture even at $N=10^{7}$ was observed. In the matrix alloy, cracks progressed only on the base surface of the notch. However, in the composite specimens, cracks were observed over the entire circumference, zigzagging over a relatively wide width range of about $5 \mathrm{~mm}$, centering on the notch. The cracks progressed in the interface between the $\mathrm{SiC}$ particle and the $\alpha$-dendrite, or in the vicinity of the $\mathrm{SiC}$ particles. In particular, many fine non-propagating cracks were intertwisting, branching and deflecting in a complicated manner in the presence of clusters of $\mathrm{SiC}$ particles in the $31 \mathrm{vol} \% \mathrm{SiC}$ specimen. The fatigue fracture surfaces about the $0.1 \mathrm{~mm}$ notches for the $9 \mathrm{vol} \%$ and $31 \mathrm{vol} \% \mathrm{SiC}$ specimens, as observed by SEM, are shown in Figs. 10 and 11. Many cracks occur on the surfaces of the specimens especially around the notch, and then the cracks progress radially toward the centers and insides of the specimens to obtain a complicated fracture surface, similarly to that for the notch- free composites. As shown in Figs. 10(b) and 11(b), clusters of $\mathrm{SiC}$ particles are observed where the cracks are generated, and an uneven fracture surface is observed around the cluster of $\mathrm{SiC}$ particles as shown in Figs. 10(c) and 11(c). The uneven fracture surface is as large as the dendrites, and smaller than in the matrix alloy. Striation pattern was also observed, as shown in Figs. 10(d) and 11(d). The progression of the crack was deflected by the $\mathrm{SiC}$ particle clusters. From the aforementioned observation, it can be concluded that, although $\mathrm{SiC}$ particle clusters work as generation points for cracks, crack propagation is sometime halted in SiC particle clusters, and then the concentration of stress in each crack is mitigated, so that the many discrete cracks do not contribute to the destruction of the specimen.

\subsection{Influence of stress concentration factor on fatigue limit stress}

The relationship between the applied stress $(\sigma)$ and the stress concentration factor $\left(K_{t}\right)$ defined by the notch depth and radius $^{23)}$ is shown in Fig. 12. Since some specimens did not break even if there was a crack, the crack generation stress $\left(\sigma_{w 1}\right)$, where cracks are initiated, and the fatigue limit stress $\left(\sigma_{w 2}\right)$, where cracks start to propagate to contribute for the fracture formation, were evaluated. $\sigma_{w 1}$ is determined by investigating the outside of a test piece in detail, and $\sigma_{w 2}$ is determined as the fatigue limit stress from the $\mathrm{S}-\mathrm{N}$ curves of Figs. 6 and 9. The highest fatigue limit stress was $140 \mathrm{MPa}$ for the matrix alloy, while the fatigue stresses were 110$120 \mathrm{MPa}$ for the composites at a $K_{t}$ of 1 (notch-free specimen). ${ }^{23)}$ No evident difference between $\sigma_{w 1}$ and $\sigma_{w 2}$ was observed. On the other hand, with a notch radius of $0.1 \mathrm{~mm}$, where $K_{t}=3.76$, the $\sigma_{w 1}$ values of all specimens decreased remarkably, to $55 \mathrm{MPa}$. Cracks are introduced forcibly by the existence of the notch, and the generation of cracks is not influenced by the distribution of $\mathrm{SiC}$ particles. However, $\sigma_{w 2}$ is unchanged with increasing $K_{t}$, and values of $95 \mathrm{MPa}$ and $105 \mathrm{MPa}$ are obtained for the 9 and $31 \mathrm{vol} \% \mathrm{SiC}$ composite specimens, although $\sigma_{w 2}$ decreases in the matrix specimen. The fatigue strength of $105 \mathrm{MPa}$ for the $31 \mathrm{vol} \%$ $\mathrm{SiC}$ specimen is almost equal to the value of $110 \mathrm{MPa}$ for the notch-free specimen.

The $\sigma_{w 1}$ and $\sigma_{w 2}$ values for each specimen are summarized in Fig. 13 in relation to the particle volume fraction. $\sigma_{w 2}$ increases with an increasing $\mathrm{SiC}$ volume fraction, and the range, over which the specimen does not break even if cracks are generated, was expanded. Thus, particle distribution would influence the crack spread, progress, connection and so on. The notch sensitivity of each specimen was evaluated on the basis of linear notch mechanics. ${ }^{24)}$ Figure 14 shows the relationship between $\sigma_{w 1}, \sigma_{w 2}, \sigma_{w 0}$ (the fatigue strength of notch-free material) and $K_{t}$. The $K_{t} \sigma_{w 2} / \sigma_{w 0}$ value for unreinforced alloy is almost unchanged at 1 to 1.5 , indicating that $\sigma_{w 2}$ lowers inversely proportional to the increasing of stress concentration. However, $K_{t} \sigma_{w 2} / \sigma_{w 0}$ increases to 3.5 for $31 \% \mathrm{SiC}$ specimen, suggesting that $\sigma_{w 2}$ improves regardless of the stress concentration and that composite specimen has the lower notch sensitivity.

The microstructure of the fatigue fracture surface in the unreinforced specimen at a 45-degree angle is shown in Fig. 15(a). The crack in the matrix alloy progressed in a 

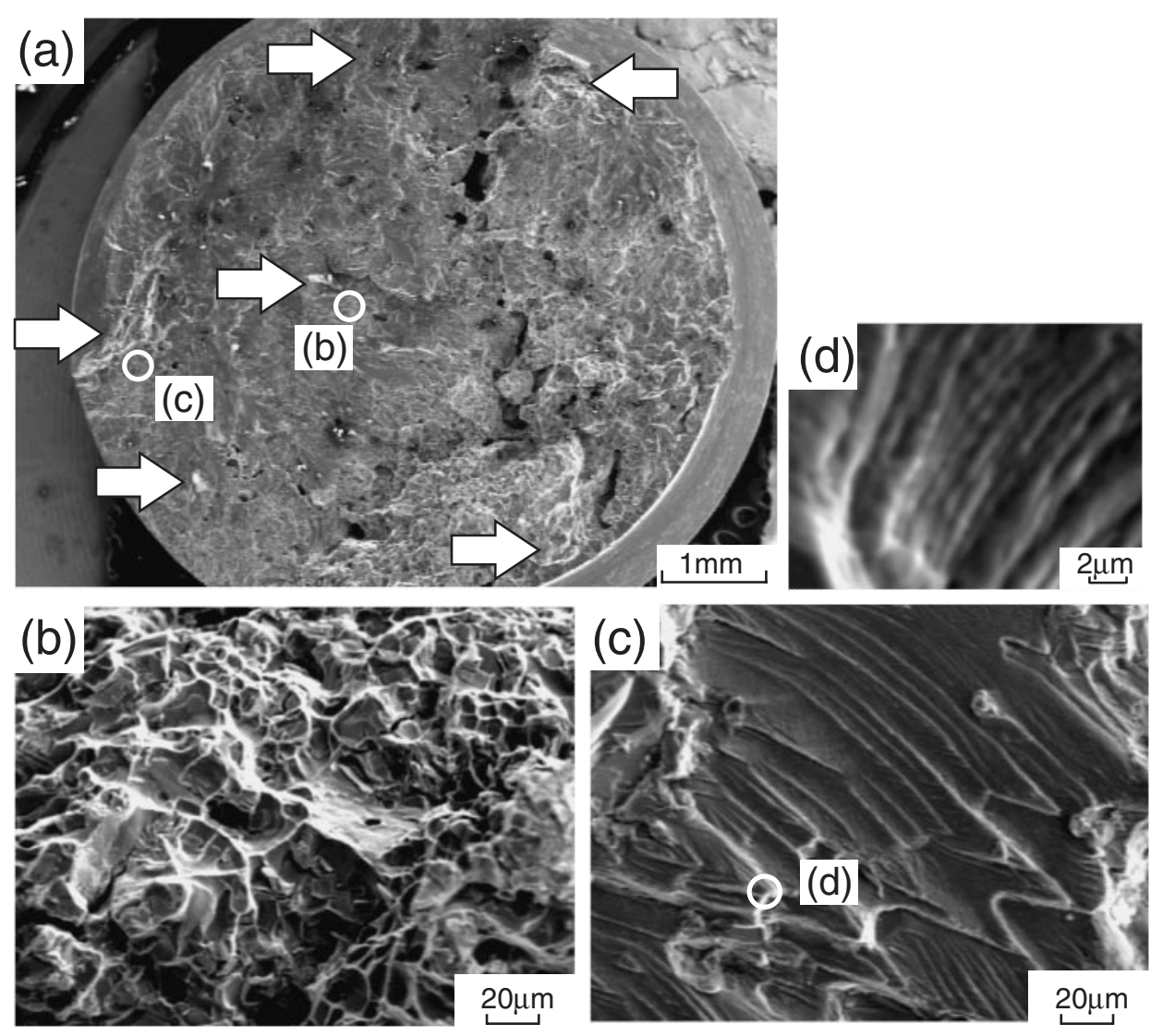

Fig. 10 Scanning electron micrographs of fractured surfaces for notched 9.3 vol\% $\mathrm{SiC} / \mathrm{AC} 4 \mathrm{~B}$ composites. The applied load is $100 \mathrm{MPa}$, and notch radius is $0.1 \mathrm{~mm}$.
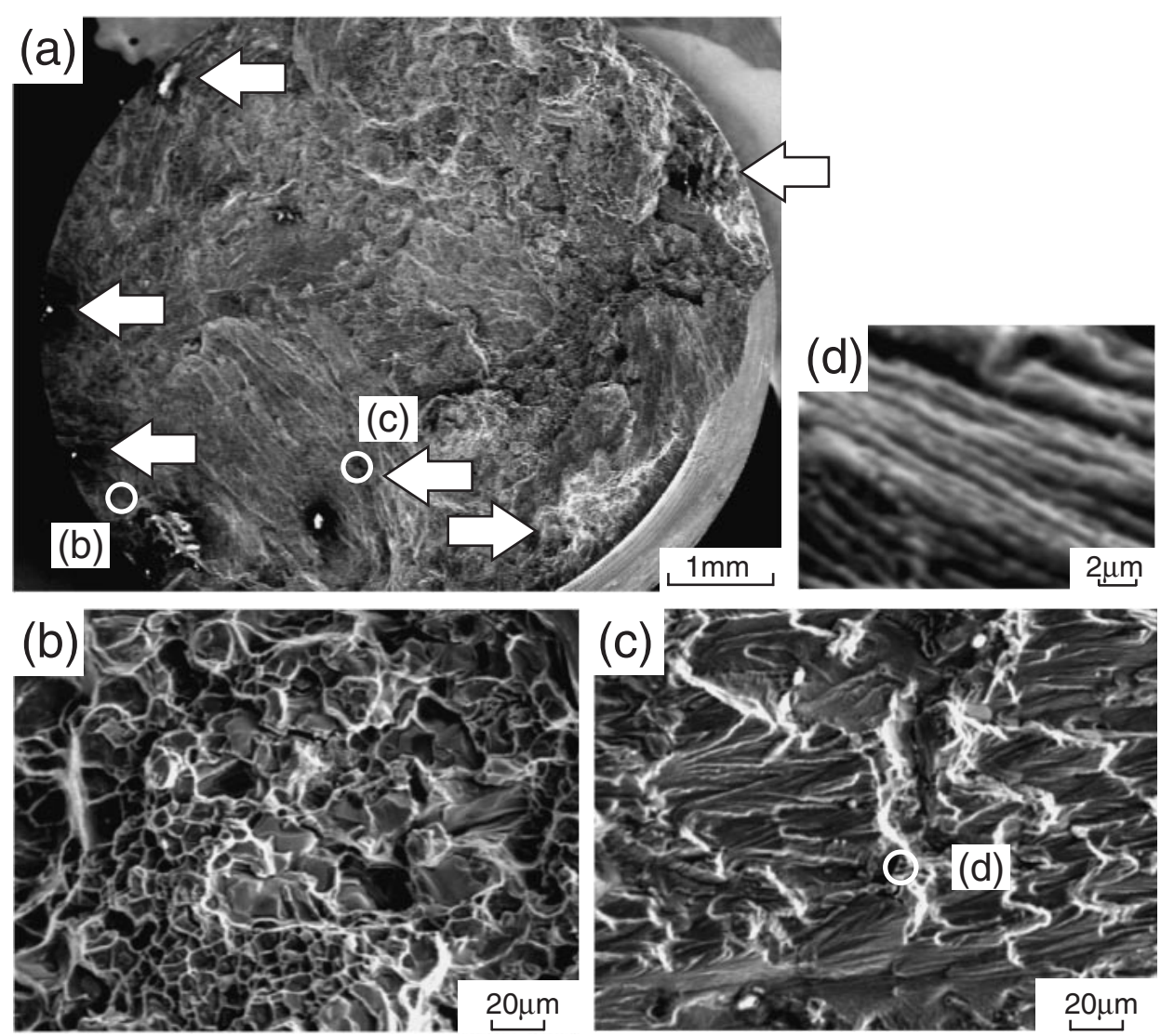

Fig. 11 Scanning electron micrographs of fractured surfaces for notched $31.4 \mathrm{vol} \% \mathrm{SiC} / \mathrm{AC} 4 \mathrm{~B}$ composites. The applied load is $110 \mathrm{MPa}$, and notch radius is $0.1 \mathrm{~mm}$. 


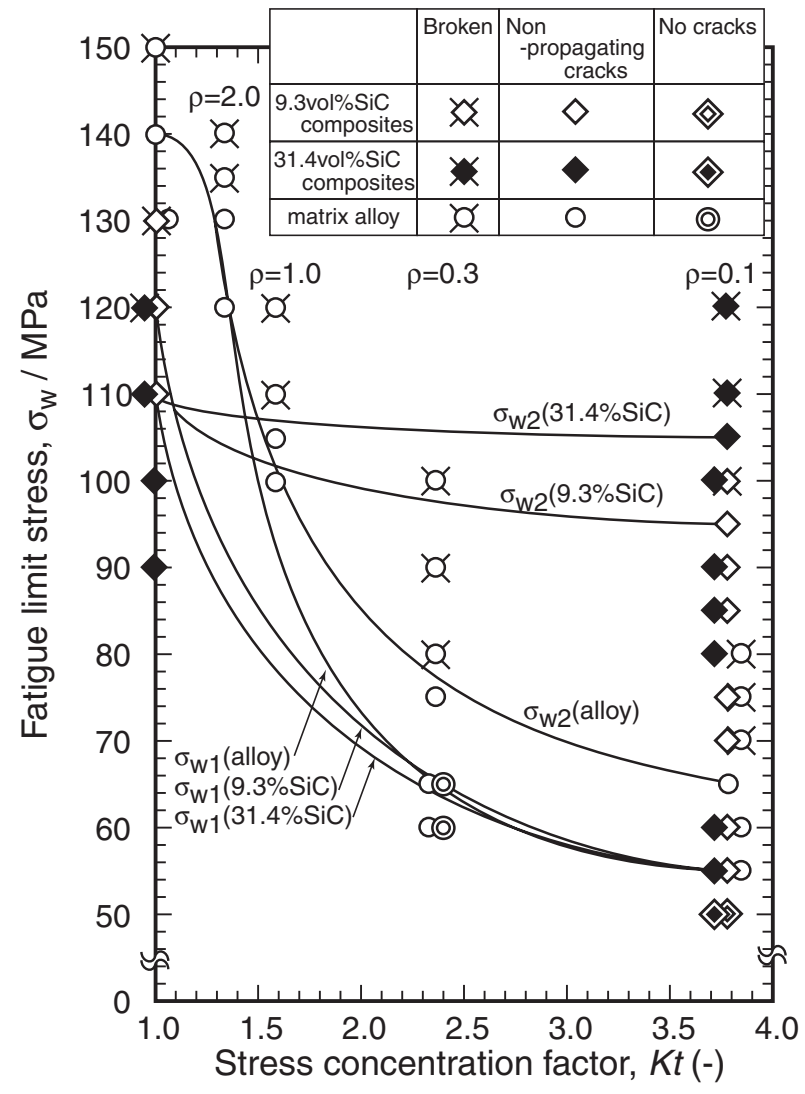

Fig. 12 Relationship between the fatigue limit stress and the stress concentration factor.

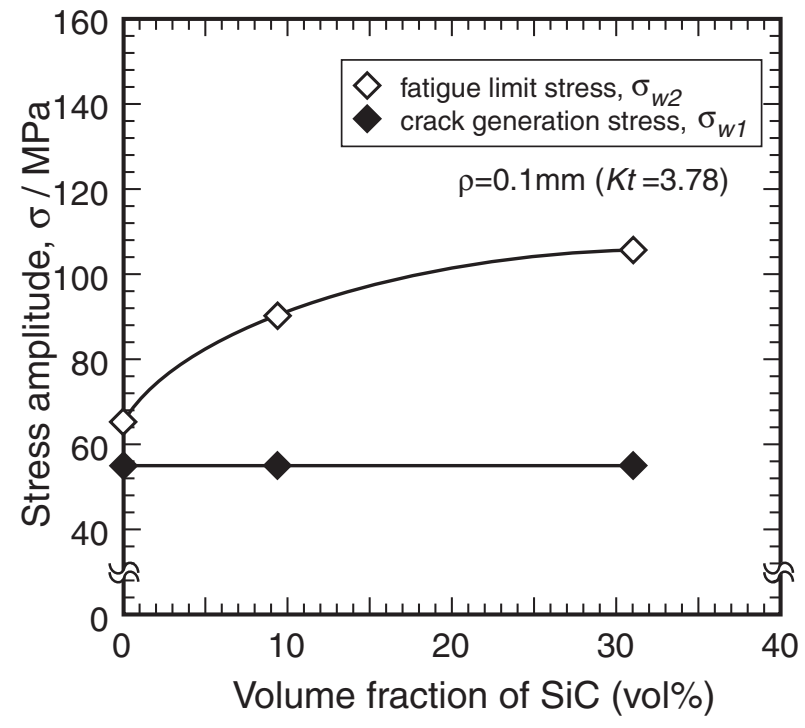

Fig. $13 \mathrm{SiC}$ volume fraction dependence of the fatigue limit stress and the crack generation stress.

straight line along the notch (Fig. 15(b)). In contrast, in the composites, the many fatigue cracks occur to a large extent everywhere, and form intense complicated fractures as shown in Fig. 15(c, d). This tendency is clearer in the $31 \mathrm{vol} \% \mathrm{SiC}$ specimen; $30 \%$ and $70 \%$ of the cracks generate from places other than the notch in the 9 and $31 \mathrm{vol} \% \mathrm{SiC}$ specimens, respectively. In these specimens, the stress

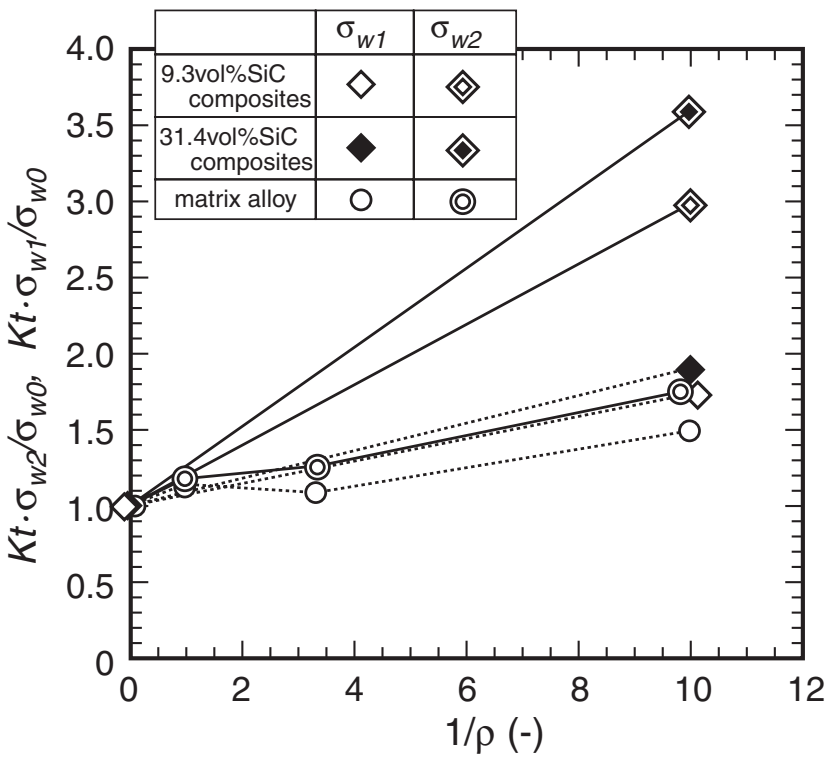

Fig. 14 Relationship between $K_{t} \sigma_{w 2} / \sigma_{w 0}, K_{t} \sigma_{w 1} / \sigma_{w 0}$ and $1 / \rho$.

concentration might be mitigated since the crack tip is branched and deflected by $\mathrm{SiC}$ particle clusters. The crack progress might also decrease because the rough crack surfaces bump into each other. Toda et al. developed the theory when the crack progress into ceramics particle reinforced alloy, and pointed out that the micro-crack, stress concentration, deposition of reinforcement from matrix and plastic deformation of matrix changed the crack propagating direction. ${ }^{11)}$ Thus, similar crack branching occurred in present condition. Furthermore, the secondary dendrite arm is shortened and the intermetallic compound densely scattered for high volume fraction composite because of the obstruction of SiC particles as shown in Fig. 3. Finer grain may also enhance the crack branching. Thus, it can be concluded that, since the frequency of inflection and branching of the crack increases with an increasing $\mathrm{SiC}$ particle volume fraction, crack propagation resistance and eventually $\sigma_{w 2}$ are improved.

\section{Conclusions}

The influence of reinforcement on dendrite growth and fatigue characteristics of a metal matrix were investigated for notched SiC particle/AC4B (Al-Cu-Si-Mg) alloy composites. The results obtained are summarized as follows:

(1) By combining pressure infiltration and melt stirring processes, it was possible to disperse $\mathrm{SiC}$ particles of specific volume fractions comparatively uniformly.

(2) The composite materials show obvious age hardening, and age hardening ability increases with an increasing $\mathrm{SiC}$ volume fraction.

(3) For unreinforced specimens, the rotating bending fatigue limit stress is influenced the notch size, and the stress decreases as notch size decreases.

(4) The SiC reinforced specimens show the same fatigue sequence in smooth and notched surface specimens, indicating that the fatigue strength is determined by the distribution of $\mathrm{SiC}$ particle clusters. 

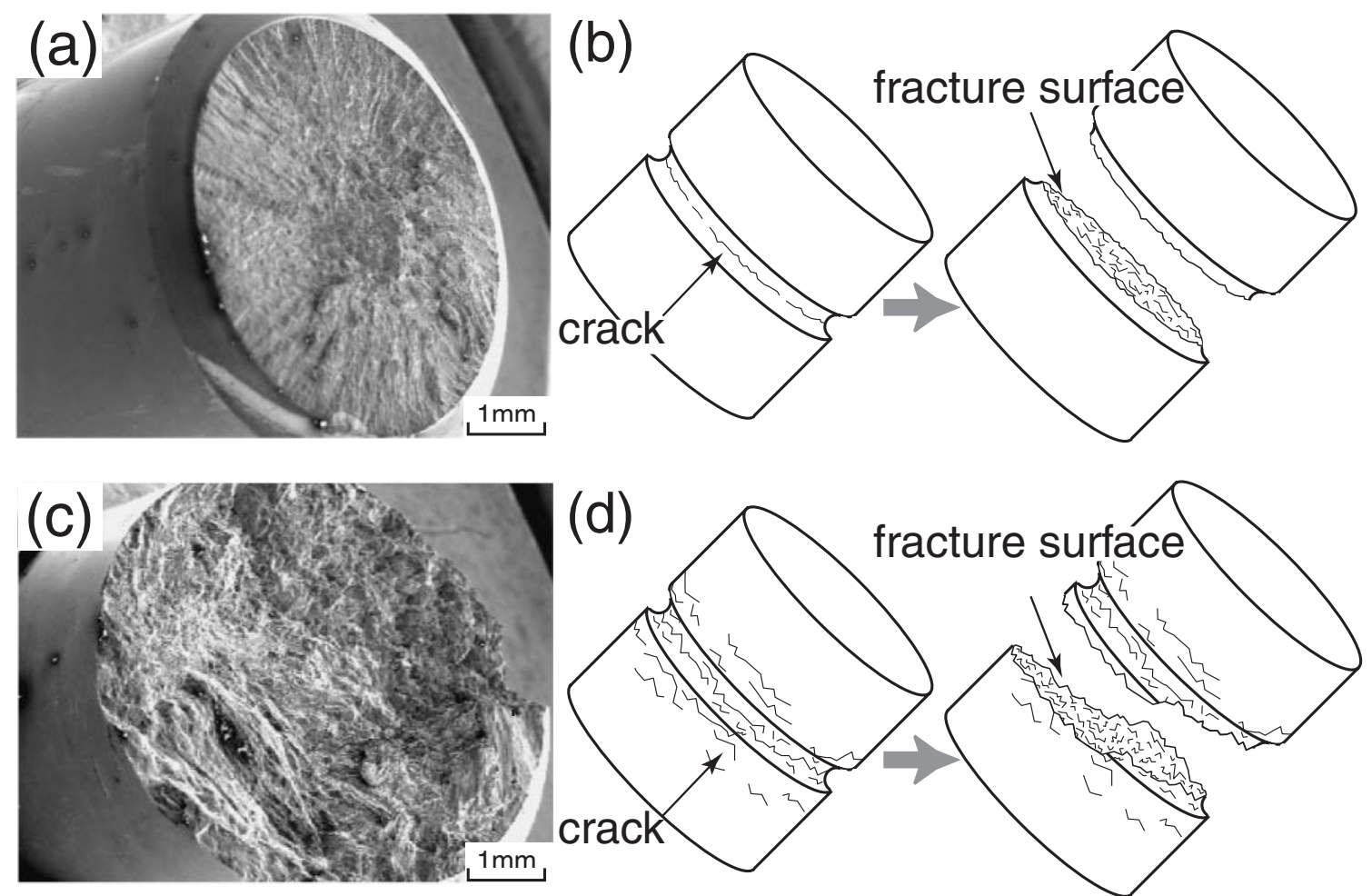

Fig. 15 Scanning electron micrographs of the fatigue fracture surfaces for unreinforced AC4B alloy (a) and $31.4 \mathrm{vol} \% \mathrm{SiC}$ reinforced composites (c) at a 45-degree angle, and schematic illustrations of fracture mechanisms in the unreinforced alloys (b) and composites (d).

(5) The clusters of SiC particles may be one of the reasons for the increase in the plastic deformation resistance against crack propagation, due to the extended crack length and the branching in crack growth directions, and eventually improve the fatigue characteristics.

\section{REFERENCES}

1) A. P. Sannio and H. J. Rack: Wear 189 (1995) 1-19.

2) T. Hikosaka, K. Miki and Y. Nishida: J. JFES 61 (1989) 780-786.

3) A. Kawabe, A. Oshida, T. Kobayashi and H. Toda: J. JILM 49 (1999) $149-154$.

4) A. Watanabe, H. Watanabe, K. Ohori and Y. Takeuchi: J. JILM 38 (1988) 626-632.

5) P. K. Rohatgi, R. Asthana and S. Das: Int. Met. Rev. 31 (1986) 115139.

6) S. V. Nair, J. K. Tien and R. C. Bates: Int. Met. Rev. 30 (1985) 275290.

7) T. S. Srivatsan and M. Al-Hajri: Compos. B33 (2002) 391-404

8) Z. Z. Chen and K. Tokaji: Mater. Lett. 58 (2004) 2314-2321.

9) N. E. Bekheet, R. M. Gadelrab, M. F. Salah and A. N. Abd El-Azim: Mater. Des. 23 (2002) 153-159.

10) L. H. Qian, Z. G. Wang, H. Toda and T. Kobayashi: Mater. Sci. Eng. A
357 (2003) 240-247

11) H. Toda and T Kobayashi: J. JILM 45 (1995) 610-621.

12) Y. Murakami: Metal Fatigue, Effects of Micro Defects and Nonmetalic Inclusions, (YOKENDO, 1993) pp. 24-32.

13) H.-G. Kang, M. Kida, H. Miyahara and K. Ogi: Int. J. Cast Met. Res. 15 (2002) 1-7.

14) S. Ikeno, K. Kawashima, K. Matsuda, H. Anada and S. Tada: J. JILM 41 (1991) 752-758.

15) R. J. Arsenault and N. Shi: Mater. Sci. Eng. 81 (1986) 175-187.

16) R. J. Arsenault and R. M. Fisher: Scr. Metall. 17 (1983) 67-71.

17) M. Vogelsang, R. J. Arsenault and R. M. Fisher: Metall. Trans. A 17A (1986) 379-389.

18) Yusaku Maruno, Hirofumi Miyahara, Hiroshi Noguchi and Keisaku Ogi: Mater. Trans. 45 (2004) 839-843.

19) H. Kobayashi: Fracture Mechanics, (KYORITU, 1993) pp. 137-146.

20) T. Araki and S. Horibe: Fatigue of Metallic Materials, (YOKENDO, 1984) pp. 46-70.

21) T. Kobayashi, T. Ito, H. J. Kim and S. Kitaoka: J. JILM 46 (1996) 437443.

22) J. Llorca, A. Needleman and S. Suresh: Acta Metall. Mater. 39 (1991) 2317-2335.

23) N. Noda, Y. Takase and K. Kadota: Science of Machine, (YOKENDO 7-48, 1996) pp. 855-860.

24) H. Nisitani: JSME 55-516 A (1989) 1733-1739. 